\title{
Failure to Align
}

National Cancer Institute

\section{Source}

National Cancer Institute. Failure to Align. NCI Thesaurus. Code C63197.

Problem associated with a circuit, equipment, or system whereby its functions fail to be properly synchronized or its relative positions properly oriented. 